\title{
SISTEM INFORMASI TROUBLESHOOTING PADA PERSONAL COMPUTER (PC)
}

\author{
Ari Widiastono ${ }^{1}$, Nur Ain Banyal ${ }^{2}$, Liza Angriani ${ }^{3}$ \\ 1ariwahyu09@gmail.com, ${ }^{2}$ nur.ain@amikumelmandiri.ac.id, ${ }^{3}$ liza.angriani@amikumelmandiri.ac.id \\ ${ }^{1,2,3} \mathrm{AMIK}$ Umel Mandiri Jayapura
}

\begin{abstract}
Abstrak
Penelitian ini bertujuan membangun sebuah perangkat lunak sistem informasi untuk menangani troubleshooting computer. Metode yang digunakan adalah Binary tree, yaitu sebuah tree dengan syarat bahwa tiap node hanya boleh memiliki maksimal 2 subtree yang disebut sebagai pohon, sub pohon kiri (left subtree), dan sub pohon kanan (right subtree), dan kedua subtree tersebut harus terpisah atau dengan kata lain tiap node dalam binary tree hanya boleh memiliki paling banyak 2 child. Hasil yang didapatkan dari sistem perangkat lunak adalah memberikan informasi mengenai solusi dari kerusakan komputer tanpa harus menyewa tenaga ahli, sehingga diharapkan dapat menekan biaya perbaikan jika terjadi kerusakan komputer.
\end{abstract}

Kata kunci: Komputer, Binary tree

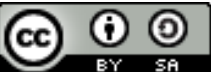

\section{Pendahuluan}

Dengan adanya kemajuan teknologi yang semakin pesat, berpengaruh pula pada perkembangan perangkat internet saat ini, sehingga penggunaan internet semakin memasyarakat. Seiring perkembangan teknologi tersebut, dikembangkan pula suatu teknologi yang mampu mengadopsi proses dan cara berfikir manusia yaitu teknologi Artificial Intelligence atau Kecerdasan Buatan.

Di sisi lain kerusakan komputer masih menjadi masalah yang cukup sulit, hal ini dapat dimaklumi mengingat banyaknya user atau pengguna komputer yang kurang memiliki pengetahuan cukup dalam penanganan kerusakan komputernya. Permasalahan ini secara umum melanda hampir semua institusi, baik itu institusi pemerintah maupun institusi swasta.

Masalahnya masyarakat umum atau suatu institusi mungkin tidak dapat mengidentifikasi di mana letak kerusakan dan berat tidaknya kerusakan yang terjadi pada komputernya. Sehingga banyak sekali institusi yang mengeluarkan biaya yang tidak sedikit hanya untuk memperbaiki kerusakan yang terjadi pada komputer. Padahal kerusakan komputer yang terjadi belum tentu rumit dan tidak dapat diperbaiki sendiri.

Untuk itu dirasakan perlunya dibangun suatu software yang dapat membantu memecahkan masalah kerusakan komputer. Software yang akan dibangun tentunya harus dapat menyajikan solusi yang tepat, akurat, masuk akal, dan efisien. Sehingga dengan pembangunan dan penggunaan software yang tepat, maka setiap institusi dapat menghemat waktu dan biaya yang seharusnya dikeluarkan untuk keperluan yang jauh lebih penting.

\section{LandasanTeori}

\subsection{Siklus Hidup Pengembangan Sistem}

Metode klasik atau tradisional yang biasa dipakai untuk mengembangkan sistem informasi adalah yang dinamakan SDLC (System Development Life Cycle). Metodologi ini mencakup kegiatan yang mengawali proyek, menganalisis kebutuhan data, merancang sistem, membuat system, dan memelihara system [1].

\subsection{Metode Binary Tree}

Binary tree atau pohon biner didefinisikan sebagai suatu kumpulan simpul atau node dengan satu elemen khusus yang disebut root dan dua sub pohon yang disebut subtree kiri dan subtree kanan.

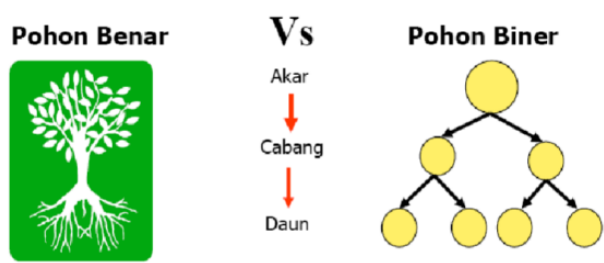

Gambar 1. Pohon Binary Tree 
Representasi binary tree salah satunya dengan menggunakan double linked list. Double linked list merupakan rangkaian dari node/simpul yang saling terhubungan dengan menggunakan pointer. Node/simpul pada double linked list terdiri dari satu bagian yang menyimpan data, dan dua bagian yang menyimpan pointer menuju ke subtree Kiri dan subtree kanan [2].
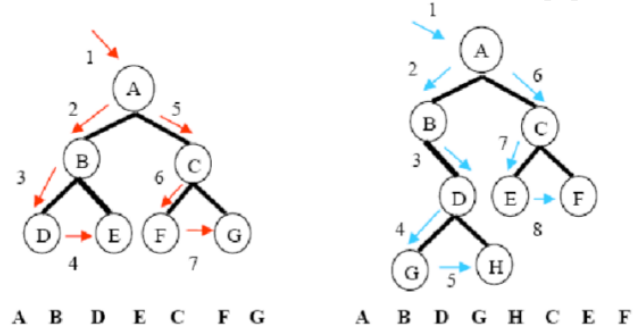

Gambar 2. Proses Penelusuran Binary Tree.

\subsection{Tabel Keputusan}

Pengetahuan relasi dapat pula direpresentasikan pada Tabel 1. Pada Tabel 1, pengetahuan disusun dalam format spreadsheet menggunakan kolom dan baris.

\begin{tabular}{|c|c|}
\hline Kode & Gejala-Gejala Kerusakan Komputer \\
\hline G01 & Komputer mati total \\
\hline G02 & Komputer sering restart \\
\hline G03 & Komputer tidak bisa booting \\
\hline G04 & Komputer sering hang \\
\hline G05 & PC kadang hidup kadang mati \\
\hline G06 & Kipas power supplay tidak berputar \\
\hline G07 & Kinerja komputer lambat \\
\hline G08 & $\begin{array}{l}\text { Tampilan dilayar ada huruf yang berkedip-kedip atau muncul } \\
\text { garis }\end{array}$ \\
\hline G09 & Layar blank \\
\hline Gn & 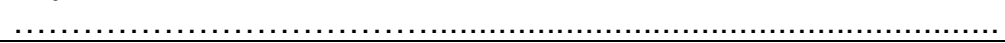 \\
\hline
\end{tabular}

\subsection{Database}

\section{Sistem Database}

Database adalah sekumpulan file data, yang umumnya mendeskripsikan aktivitas satu organisasi yang berhubungan atau lebih dari satu organisasi yang terkait, misalnya database universitas mungkin berisi informasi sebagai berikut:

a. Entitas seperti mahasiswa, fakultas, mata kuliah, dan ruang kuliah.

b. Hubungan antara entitas, seperti registrasi mahasiswa dalam mata kuliah, fakultas yang mengajarkan mata kuliah, dan penggunaan ruang kuliah.

Sistem Database adalah sekumpulan file data yang saling berhubungan dan diorganisasi sedemikian rupa sehingga memudahkan untuk mendapat dan memproses data. Sebuah database harus dibuat dengan rapi agar setiap data yang dimasukkan sesuai dengan tempatnya.

2. Database Relasional

Database relasional adalah jenis database yang menggunakan model relasional. Pada model relasional, data disusun dalam bentuk sejumlah relasi dan table. Untuk kepentingan menangani database, sejumlah DBMS (Database Management Sistems) tersedia di pasaran, diantaranya yaitu MySQL [3].

\section{Metode}

Metode yang digunakan dalam pencarian solusi troubleshooting pada personal computer yang akan dibangun adalah metode binary tree. Implementasi metode binary tree dalam pencarian solusi troubleshooting computer dapat dilihat pada Gambar 3. 


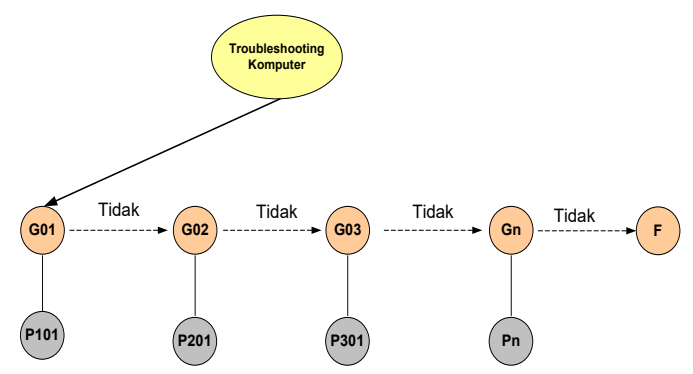

Gambar 3. Binary Tree Troubleshooting Komputer

Langkah-langkah pencarian troubleshooting komputer.

1. Pencarian troubleshooting komputer dimulai dengan gejala G01 di mana G01 adalah gejala komputer mati total. Jika user memilih YA maka proses pencarian akan dilakukan. Dari gejala G01, sistem akan memberikan pertanyaan gejala (P101) yang harus dijawab oleh user, jika user menjawab [Ya] maka solusi [S101] untuk memecahkan masalah troubleshooting yang dialami user ditemukan. Jika user menjawab [Tidak], maka sistem akan memberikan pertanyaan gejala (P102) selanjutnya sampai solusi ditemukan. Jika Solusi (S) belum juga ditemukan maka sistem akan mengalihkan ke forum $(F)$, forum disini berupa usulan user ke sistem berupa solusi yang belum terpecahkan oleh sistem (Gambar 4).

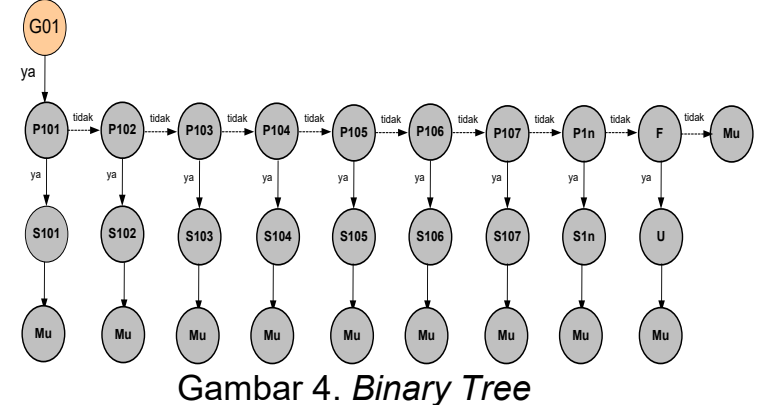

Pencarian Gejala Kerusakan Komputer Mati Total (G01)

2. Dari gejala G01, Jika user memilih Tidak maka proses pencarian akan dilanjutkan ke gejala G02, dimana G02 adalah gejala komputer sering restar. Dari gejala G02, sistem akan memberikan pertanyaan gejala (P201) yang harus dijawab oleh user, jika user menjawab [Ya] maka solusi (S201) untuk memecahkan masalah troubleshooting yang dialami user ditemukan. Jika user menjawab [Tidak], maka sistem akan memberikan pertanyaan gejala (P202) selanjutnya sampai solusi ditemukan. Jika Solusi (S) belum juga ditemukan maka sistem akan mengalihkan ke forum $(F)$, forum disini berupa usulan user ke sistem berupa solusi yang belum terpecahkan oleh sistem (Gambar 5).

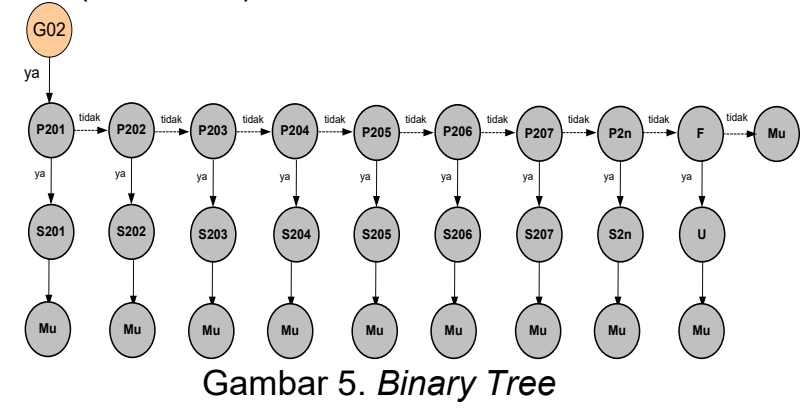

Pencarian Gejala Kerusakan Komputer Sering Restar (G02)

3. Dari gejala G02, Jika user memilih Tidak maka proses pencarian akan dilanjutkan ke gejala G03, dimana G03 adalah gejala komputer tidak bisa booting. Dari gejala G03, sistem akan memberikan pertanyaan gejala (P301) yang harus dijawab oleh user, jika user menjawab [Ya] maka solusi (S301) untuk memecahkan masalah troubleshooting yang dialami user ditemukan. Jika user menjawab [Tidak], maka sistem akan memberikan pertanyaan gejala (P302) selanjutnya sampai solusi ditemukan. Jika Solusi (S) belum juga ditemukan maka sistem akan mengalihkan ke forum ( $F)$, forum disini berupa usulan user ke sistem berupa solusi yang belum terpecahkan oleh sistem (Gambar 6). 


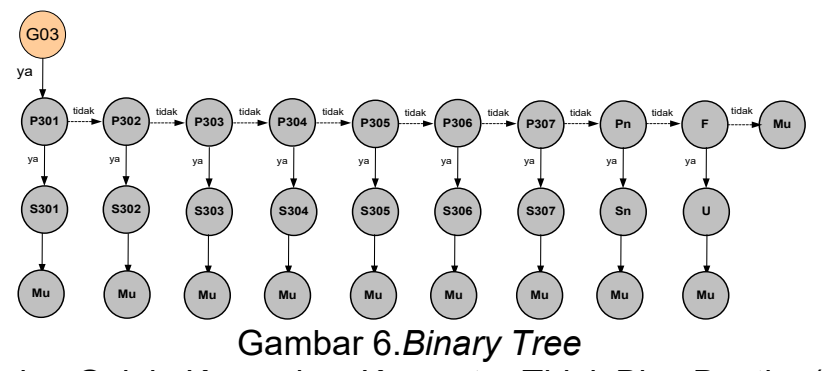

Pencarian Gejala Kerusakan Komputer Tidak Bisa Booting( G03)

4. Dari gejala G03, Jika user memilih Tidak maka proses pencarian akan dilanjutkan ke gejala Gn, dimana $\mathrm{Gn}$ adalah gejala kerusakan selanjutnya. Dari gejala $\mathrm{Gn}$, sistem akan memberikan pertanyaan gejala (Pn) yang harus dijawab oleh user, jika user menjawab [Ya] maka solusi (Sn) untuk memecahkan masalah troubleshooting yang dialami user ditemukan. Jika user menjawab [Tidak], maka sistem akan memberikan pertanyaan gejala $(\mathrm{Pn})$ selanjutnya sampai solusi ditemukan. Jika gejala kerusakan komputer $(G n)$ tidak ditemukan maka sistem akan mengalihkan ke forum $(F)$, forum disini berupa usulan user ke sistem berupa gejala kerusakan komputer yang tidak ada didalam sistem.

\section{Hasil dan Pembahasan}

\subsection{Implementasi Antar Muka}

Implemantasi antar muka merupakan tampilan untuk pengguna aplikasi.Implemantasi antar muka disini dibuat menggunakan bahasa pemrogaman PHP.

\section{Antar Muka Menu Utama}

Form utama digunakan untuk pusat dari menu program, melalui form ini semua proses dapat dipanggil dan dapat digunakan. Fungsi menu utama ini digunakan untuk mengakses ke form lainnya yaitu form konsultasi, form perangkat, dan form tentang sistem informasi. Form utama dapat dilihat pada Gambar 7.

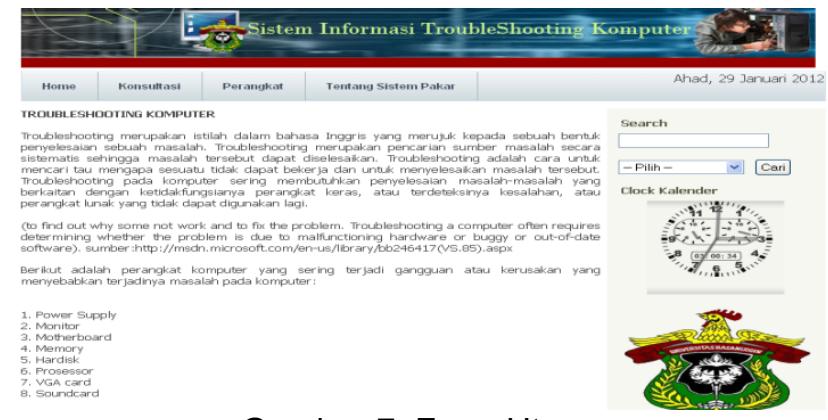

Gambar 7. Form Utama

\section{Antar Muka Form Konsultasi}

Pada menu konsultasi yang pertama dilakukan adalah user menjawab gejala-gejala kerusakan komputer yang diajukan oleh sistem. Sebagai contoh user menjawab gejala komputer mati total (Gambar 8).

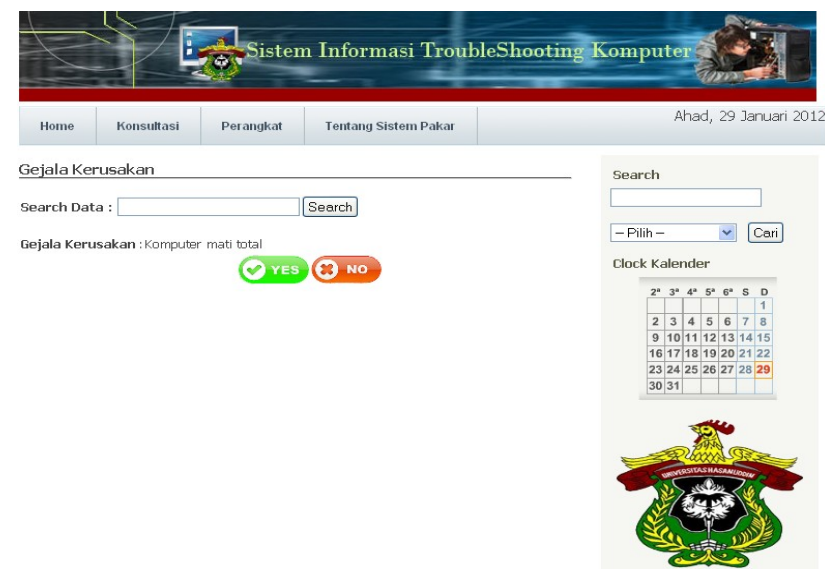

Gambar 8. Form Konsultasi 
Jika user menjawab Yes, maka proses pencarian gejala komputer mati total ditelusuri. Sistem akan menampilkan pertanyaan mengenai gejala komputer mati total (Gambar 9).

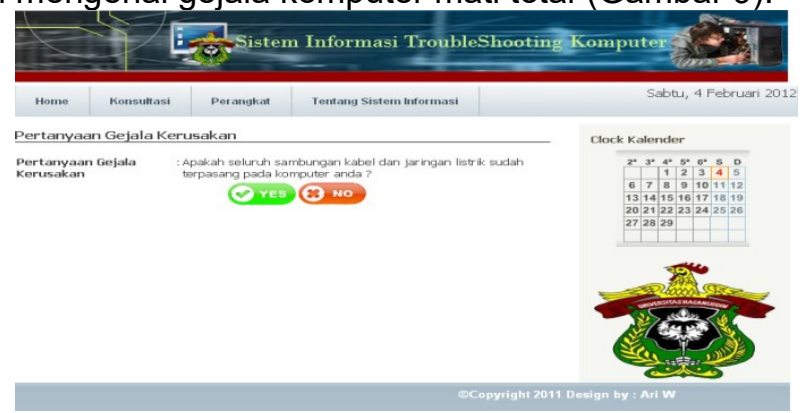

Gambar 9. Tampilan Pertanyaan

Jika user menjawab Yes, maka sistem akan menampilkan solusi dari pertanyaan komputer mati (Gambar 10).

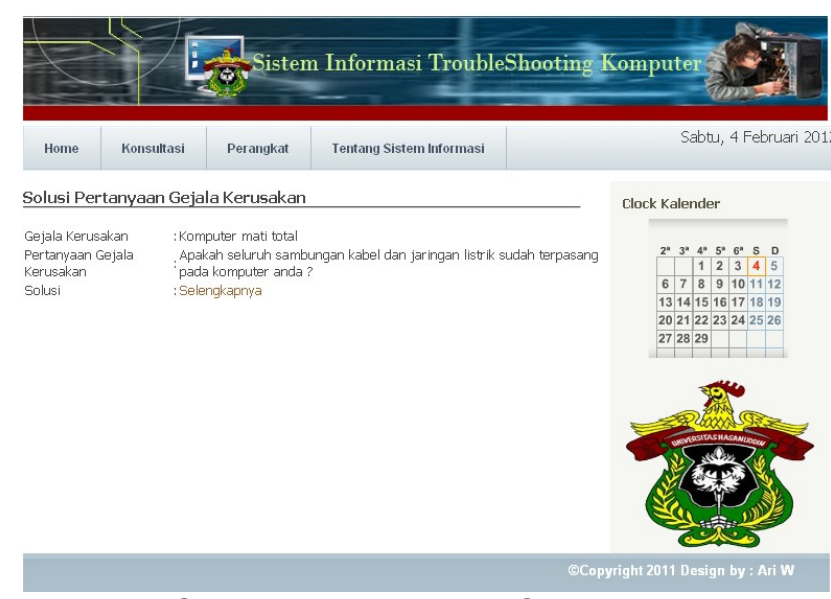

Gambar 10. Tampilan Solusi Pertanyaan

Jika user menjawab Tidak maka sistem akan menampilkan pertanyaan kedua (2) gejala kerusakan komputer mati total (Gambar 11).

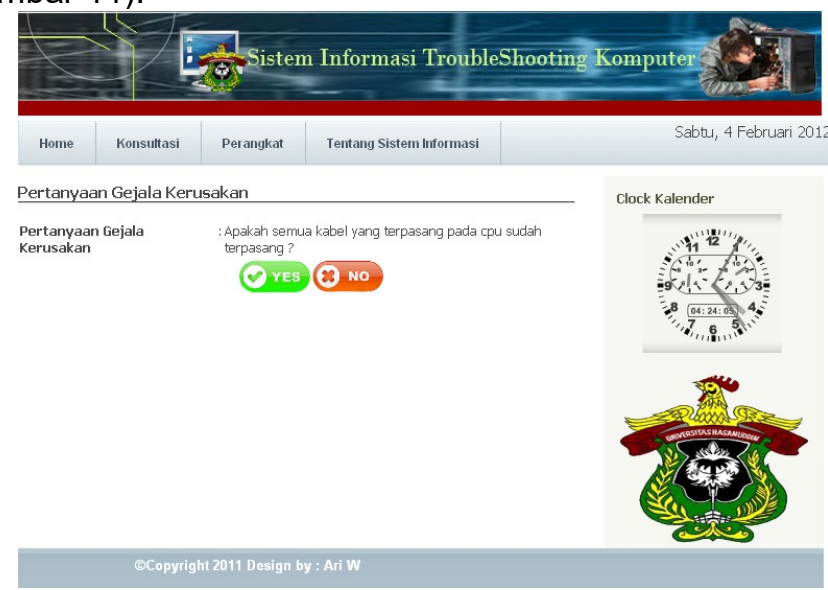

Gambar 11. Tampilan Pertanyaan

Jika pertanyaan dari sistem belum terjawab mengenai gejala kerusakan komputer mati total maka sistem akan menampilkan form usulan. Form usulan disini adalah usulan masalah yang belum terjawab dari hasil konsultasi/diagnosis oleh system (Gambar 12). 


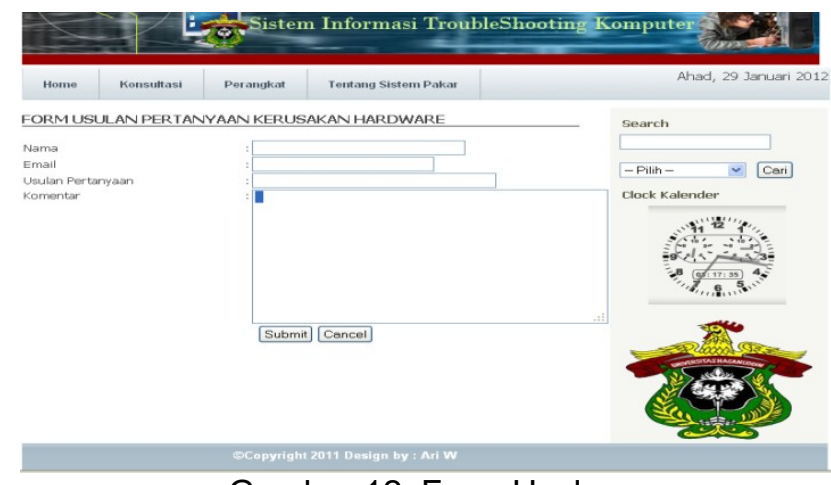

Gambar 12. Form Usulan

3. Antar Muka Perangkat

Form perangkat disini berisi tentang informasi perangkat-perangkat yang ada di dalam komputer (Gambar 13).

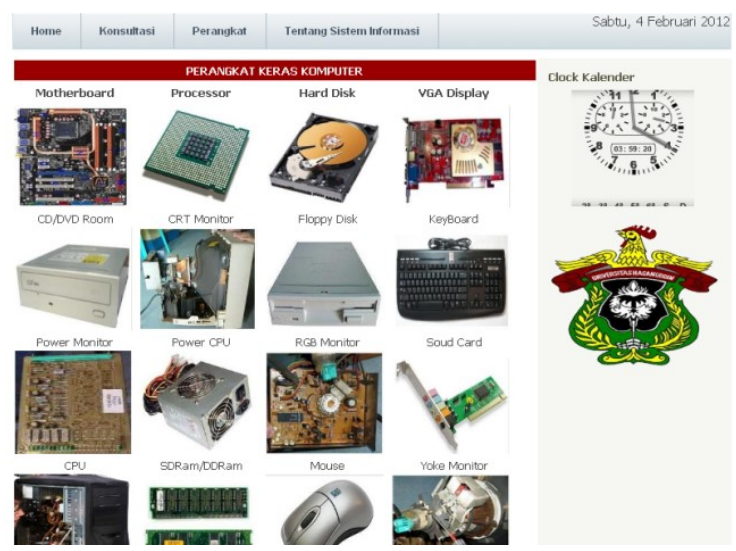

Gambar 13. Form Perangkat

4. Form Tentang Sistem Informasi

Form tentang sistem informasi berisi tentang penjelasan sistem informasi (Gambar 14).

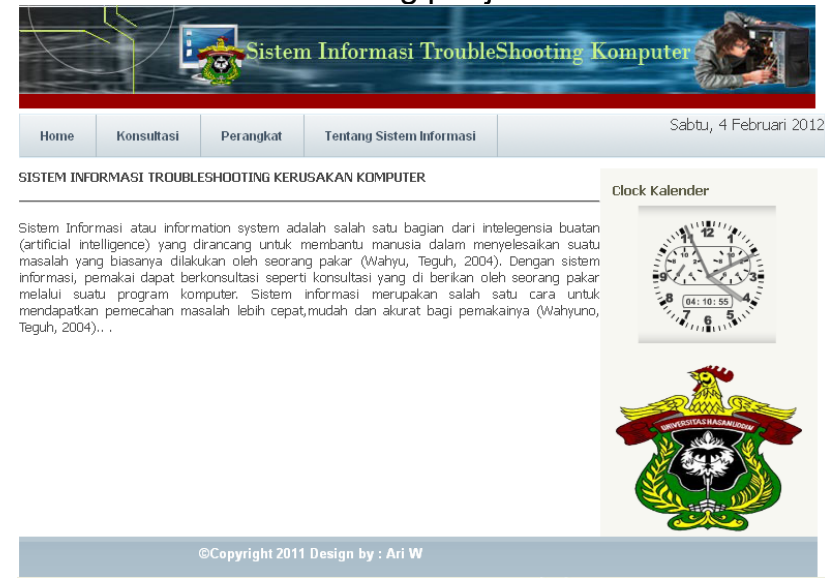

Gambar 14. Form Tentang Sistem Informasi

\subsection{Pengujian Sistem}

Pengujian yang dilakukan adalah pengujian black box. Pengujian ini berdasar pada analisis dan perancangan sistem. Pengujian dilakukan pada sistem untuk memastikan penerapan perangkat lunak telah sesuai dengan fungsinya. Permasalahan yang umum dipertanyakan pada pengujian adalah apakah sistem telah dikembangkan dengan cara yang benar dan sudah sesuai dengan spesifikasi.

Proses analisisnya dengan cara melihat penerapan-penerapan dari spesifikasi sistem yang dibangun. Oleh karena sistem telah dibangun sesuai metode yang direncanakan, maka dapat disimpulkan sistem pakar troubleshooting pada komputer ini telah memenuhi pengujian black box.

Pengujian dilakukan dengan 2 (dua) tahap yaitu:

a. Pengujian fungsi dari masing-masing menu

b. Pengujian metode 
a. Pengujian fungsi dari masing-masing menu

1. Pengujian Menu User dapat dilihat pada Gambar 15.

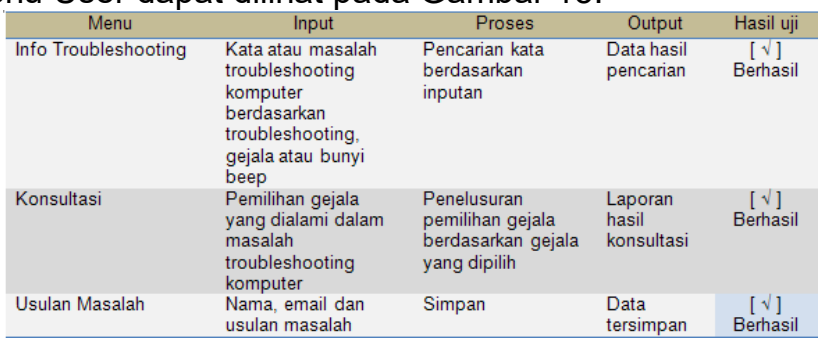

Gambar 15. Pengujian Menu User

2. Pengujian Menu Admin dapat dilihat pada Gambar 16.

\begin{tabular}{|c|c|c|c|c|}
\hline Menu & Input & Proses & Output & Hasil uji \\
\hline $\begin{array}{c}\text { Gejala } \\
\text { kerusakan } \\
\text { hadware }\end{array}$ & $\begin{array}{l}\text { Kode, kerusakan hadware, } \\
\text { gejala-gejala kerusakan } \\
\text { hadware, pertanyaan gejala } \\
\text { kerusakan hadware, solusi } \\
\text { kerusakan hadware }\end{array}$ & $\begin{array}{l}\text { Simpan } \\
\text { Edit } \\
\text { Hapus }\end{array}$ & $\begin{array}{c}\text { Data } \\
\text { tersimpan }\end{array}$ & {$[\sqrt{ }$ ] Berhasil } \\
\hline $\begin{array}{c}\text { Gejala } \\
\text { kerusakan } \\
\text { sistem operasi }\end{array}$ & $\begin{array}{c}\text { Kode, gejala-gejala } \\
\text { kerusakan sistem operasi } \\
\text { pertanyaan gejala } \\
\text { kerusakan sistem operasi, } \\
\text { solusi kerusakan sistem } \\
\text { operasi }\end{array}$ & $\begin{array}{c}\text { Simpan } \\
\text { Edit } \\
\text { Hapus }\end{array}$ & $\begin{array}{c}\text { Data } \\
\text { tersimpan }\end{array}$ & {$[\sqrt{ }$ ] Berhasil } \\
\hline $\begin{array}{c}\text { Gejala } \\
\text { kerusakan } \\
\text { program aplikasi }\end{array}$ & $\begin{array}{l}\text { Kode, gejala-gejala } \\
\text { kerusakan program aplikasi } \\
\text { pertanyaan gejala } \\
\text { kerusakan program aplikasi, } \\
\text { solusi kerusakan program } \\
\text { aplikasi }\end{array}$ & $\begin{array}{c}\text { Simpan } \\
\text { Edit } \\
\text { Hapus }\end{array}$ & $\begin{array}{c}\text { Data } \\
\text { tersimpan }\end{array}$ & {$[\sqrt{ }]$ Berhasil } \\
\hline $\begin{array}{c}\text { Gejala } \\
\text { kerusakan bunyi } \\
\text { beep }\end{array}$ & $\begin{array}{c}\text { Kode, gejala-gejala } \\
\text { kerusakan bunyi beep, } \\
\text { pertanyaan gejala } \\
\text { kerusakan bunyi beep, } \\
\text { solusi kerusakan bunyi } \\
\text { beep }\end{array}$ & $\begin{array}{c}\text { Simpan } \\
\text { Edit } \\
\text { Hapus }\end{array}$ & $\begin{array}{c}\text { Data } \\
\text { tersimpan }\end{array}$ & {$[\sqrt{ }]$ Berhasil } \\
\hline
\end{tabular}

Gambar 16. Pengujian Menu Admin

b. Pengujian Metode

Pengujian metode bertujuan untuk melihat apakah sistem yang dikembangkan berhasil memecahkan/menjawab permasalahan terhadap kerusakan (troubleshooting) pada komputer. Berikut ini beberapa sampel hasil uji coba dengan menggunakan aplikasi troubleshooting komputer dapat dilihat pada Gambar 17 A dan B.

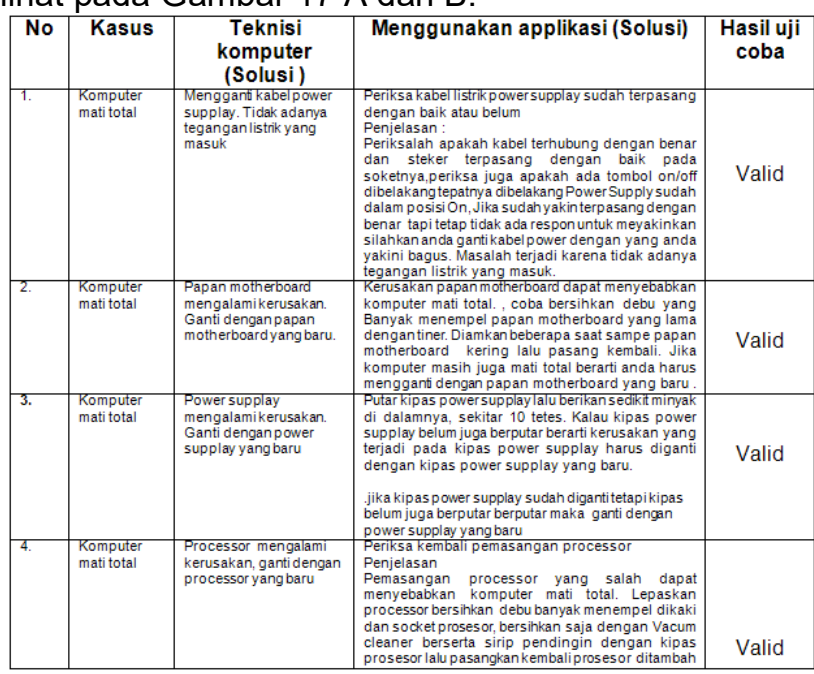

Gambar 17. a. Pengujian Metode 


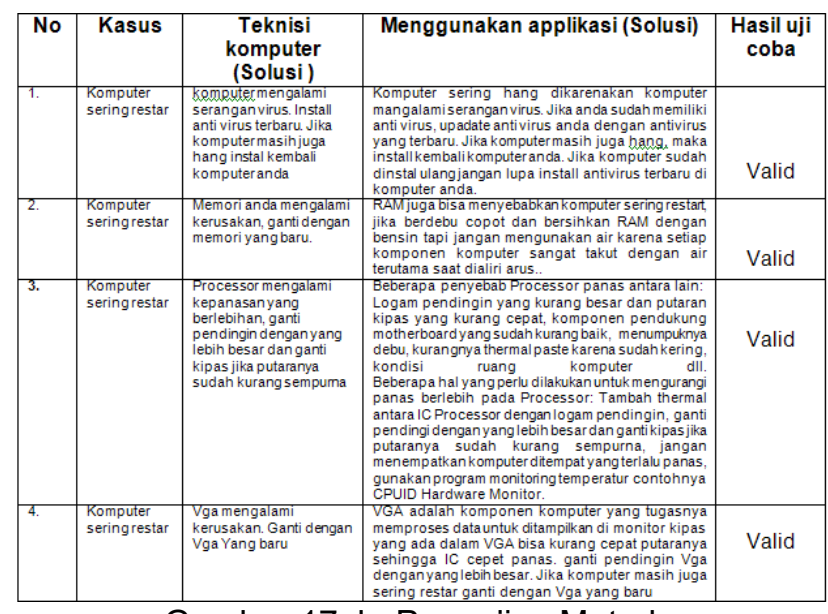

Gambar 17. b. Pengujian Metode

\section{Kesimpulan dan Saran}

\subsection{Kesimpulan}

1. Dengan dibangunnya perangkat lunak sistem informasi troubleshooting kerusakan komputer, diharapkan dapat membantu seseorang yang ingin mengetahui kerusakan pada PC-nya secara akurat dan tepat.

2. Aplikasi ini dapat digunakan oleh banyak orang, sehingga seseorang dapat memperbaiki PCnya secara cepat dan tepat. Aplikasi system informasi troubleshooting komputer, memberikan kemudahan informasi kepada user komputer dalam menemukan letak permasalahan yang terjadi pada komputernya tanpa harus menyewa tenaga ahli, sehingga diharapkan dapat menekan biaya perbaikan jika terjadi kerusakan komputer.

3. Aplikasi ini dibuat berdasarkan gejala-gejala kerusakan komputer yang dialami user. Untuk bisa memakai aplikasi ini user harus terhubung dahulu dengan internet.

\subsection{Saran}

1. Diharapkan adanya penelitian lanjutan dari sistem informasi ini sehingga mendapatkan hasil yang lebih efesien.

2. Aplikasi ini belumlah dapat mengakomodir semua kerusakan komputer, karena itu diharapkan aplikasi ini dapat lebih dikembangkan agar dapat mendiagnosa semua jenis kerusakan komputer.

3. Aplikasi ini diharapkan agar dapat terus mengikuti perkembangan zaman sehingga selalu up to date untuk digunakan dengan tampilan yang lebih menarik minat pemakai.

\section{Daftar Pustaka}

[1] Al Bahra bin Ladjamudin. 2005. Analisis dan Desain Sistem Informasi. Graha IImu. Yogyakarta.

[2] I Made Sukarsa dan Ni Wayan Wiswani. 2009. Rancang Bangun Sistem Pakar untuk Perbaikan Kecepatan dan Kegagalan Koneksi Peralatan External pada Personal Komputer. Jurnal Fakultas Universitas Muhammadiyah Gresik.

[3] Nugroho Bunafit. 2004. Aplikasi Pemrograman Web Dinamis dengan PHP dan MySQL. Gava Media. Edisi Pertama. Yogyakarta. 